\title{
An Empirical Analysis of the Growth-Health Relationship in Pakistan
}

\author{
Nayab Khalid* \& Aaqib Qayyum \\ Department of Economics, University of Wah, Wah Cantt, Pakistan
}

\begin{abstract}
The purpose of this study is to examine Pakistan's health sector issues and the critical ties between health indicators and economic growth. ARDL analysis has been applied on the data set of Pakistan's economy, in the time reference to 1990-2020. The study revealed that the important ties between GDP, foreign direct investment, fertility and life expectation in the short run are strong, while mortality rate is negative, but have a significant impact on economic development. The fertility rate has a huge effect on GDP in long-term, while affecting foreign direct investment. The study achieves that countries with developing economic growth will focus more on improving human capital well-being.
\end{abstract}

Keywords: Economic growth; Health indicators; Mortality rate; Life expectancy; GDP; Pakistan.

\section{Introduction}

Health is one of the major reasons for a man to gain productivity or profitability, as a healthy person can get best in his life whether it is the matter of money or fame, he can acquire each and every thing in his life which he desires. As indicated by World Health Organization (WHO), health is denoted as the state of getting prosperity and social well being.it is not just because of the absence of sickness or illness. A Productive PERSON plays a very vital role in the progress of any nation, as they are more profitable or money- making than non-productive people. Profitability of an individual or a productive person can be estimated through his profit. A healthy individual attains more in money and fame as compared to less healthy individual. Nations with healthy employees can get success in every matter of life, Ahsan et al. (2014). As per the WB report of $2005,50 \%$ of growth in the economy is due to inadequate wellbeing, shorter life expectancy among developed and emerging nations, Renny (2012). As, Lucus (1988) properly characterized human capital as the motor of financial development. In the year 2005, a report was produced by international forum, explaining the main differences between high and low-income nations; that $50 \%$ of economy is affected by low expectancy of the country's population, Renny (2012).

The effect of any kind on health does affect the profitability of a labour in certain ways because health directly effects a person economically as well as socially.in short health plays an important role for any body's success. Healthy laborers don't waste their time during their work because of their good health so they are more profitable and productive in their work. Healthiness also give us financial outcomes, as Abad health leads us towards poverty and good health towards prosperity, World Health Organization (1999). It is of unbelievable significance that the connection between health indicators and economic development should be examined keeping in mind the end goal to detail star development strategies with uncommon reference to economies like Pakistan. The requirement between health as usage and decent resources had been explained by, Grossman (1972).

As it happened that, with providing best health benefits, people enjoy well and they do not really waste more days mostly in house as ill, since they need more days to work to undertake notable business and activity.

\footnotetext{
* Corresponding author.

E-mail address: nayabkhalid481@gmail.com (Nayab Khalid)
} 
The health sector must be strengthened for the economic development of Pakistan, which will bring stability at the end of the day. The economic development of health, socioeconomic, technological and political causes, genetic wealth, quality of life, work environment and so forth has many impacts. By enhanced workforce productivity, enhanced aggregate demand, improving training or post-secondary qualifications, healthcare will boost job creation. New technologies can be handled very well by physically and mindfully balanced workers and thereby benefit the economy.

Grossman (1972), had clarifies the requirements of health and capital. As both are correlated to on another. The utilization of health entails that, individuals appreciate when they have good health and sound body. Because they don't want to sit idle in the days of sickness. They need to work to compete the market, thus for the economic growth of Pakistan, health sector must be improved which can ultimately bring prosperity. Health can spur economic growth, through enhancing efficiency of labour, enhancing labour supply, enhancing the skills due to training or higher education. Improved health facilities and better standard of living of people tends to contribute to the healthy economy. A labour can get wage score which does relate with the productivity of a labour and this productivity increases by better health conditions. In any country, the level of productivity can only be increased by increasing the level of education for people. It is keenly noticed that the people who are healthy, have more possibilities to get education bitterly as compare to unhealthy people, Muhammad Omer Chaudhry (2013).

Enhancing the health and life span of the poor is an end in it-self, a crucial objective of economic development. Be that as it may, it is additionally a way to accomplish the other advancement objectives identifying with deprivation. The relationship of health with deprivation decline and to long term economic growth is strong, significantly higher. The issue of disorders in some low-pay areas, particularly sub-Saharan Africa, remains clear limitation to economic development and in this manner must be tended to directly and centrally in any thorough improvement technique, Sachs (2001). Health is a necessary part of human capital. It will continue the productivity of workers by extending their physical boundaries, for example, consistency and continuation, and even their mental and psychological limits. It can continue laborers efficiency by expanding their physical limits, for example, quality and continuance, and also their psychological limits, for example, subject i.e. working and thinking capacity.

The nation's supreme authority is Government. The responsibility of education, social development and health of the people depends on its Government. Any state who is taking care of t heir people is getting success and high GDP growth rate. The country which is sincere for the growth of its people, works on development and health care of the nation's people, Bentham (2016). In the year 1990's the life expectancy (at birth) in Pakistan was 60.1 years and now in 2016 the life expectancy is raised from 60.1 years to 66.5 years, in the matter mortality rate (per 1,000 live births) from year 1990-2015, also decreased from 106.2 to 65.7 respectively, World Bank (2016). The death rate of infant children got decreased by vaccination in their most early stages of lives, due to which life expectancy rate is increasing day by day. It is also a good sign for a state that people of the state are healthy and escaping their lives from different kind of diseases, by defending themselves against diseases, so economic growth increases.

This study examined the effect of health indicators on the financial development of Pakistan, using the annual time series from 1990 to 2020 by considering GDP per capita taken as dependent variable financial development and selected health indicators used i.e. Life expectancy, health expenditure, Infant mortality rate, Fertility rate and foreign direct investment are the independent variables.

\section{Literature Review}

Bhargava et al. (2001) explored the impacts of wellbeing markers on monetary development. Future, youngster ethical quality, grown- u p survival rates, was utilized as free factors to watch their effect on GDP development. Panel information arrangement were utilized for examination. In this examination paper on GDP arrangement in light of obtaining power modifications and a GDP arrangement in light of authority trade rates and utilized a few econometric philosophies. It was imperative to utilized two options GDP arrangement as a result of obtaining power correlations.

Barro (1991) dissected the information of 95 nations for the time of 1960-85. They found that development rate of real per capita GDP is decidedly related with starting level of human capital intermediary by optional school enlistment in 1960. They additionally examined the effect of fruitfulness on financial development and the aftereffects of their relapse clarified that the nations that have higher instructive human capital have bring down 
ripeness and high development rates of genuine per capita GDP. Mincer (1996) clarify that human capital isn't just aim of financial development but at the same time is an impact. It is clarified that higher financial development through increment in family wage, urbanization, statistic change and expanded female work constrain investment human capital supply increment and then again because of higher physical capital collection and innovative advance interest for talented work increments. The cooperation of free market activity of human capital outcomes in expanded interest in training. It is proposed that this equal relationship is basic for maintained monetary development.

Musila et al. (2004) researched the relationship of human capital venture and monetary development in Uganda utilizing yearly information on GDP and open use on training for the time of 1965 to 1999. The error correction model and integration test evaluation confirmed the short-term and long-term link between GDP and human resources. The probability proportion test likewise affirmed that training uses are pitifully exogenous, so they instruction consumption contribute altogether to expand GDP of the nation. Abbas et al. (2000) analysed the effect of human capital in Pakistan and India on monetary growth. He used a bookkeeping method to focus on the effect on macroeconomic knowledge from 1970 to 1994 using the OLS methodology. The prices for registration in this test were taken as a main intermediary for human resources at subsidiary and higher optional stages. For various intermediaries of human capital, the outcomes were unique. Auxiliary tutoring was observed to be decidedly related and noteworthy in both the nations however essential instruction was observed to be emphatically related in the event of India at $1 \%$ level of hugeness and higher optional training was discovered decidedly related in the event of Pakistan at $10 \%$ level of criticalness.

Khan et al. (2005) inspected the elements that add to financial development. He took the example of 72 nations of low and centre pay gathering. The day and age were from 1960-2002. He made cross-segment examinations by taking the normal of the factors over the period 1980-2002. OLS evaluations of the relapse uncover that human capital is huge factor in deciding development. Also, for Pakistan to enter in the high-minded cycle interest in medicinal services and training ought to be given the need. Abbas et al. (2008) examine the link in Pakistan with aggregate data on time series among human wealth and monetary progress. The fitted model was assessed using Johansen (1991) as a critical component of human cash flow in order to improve the economy 's ability to achieve innovative worldwide advances. Ahsan et al. (2014) researcher investigate effect of human efficiency, estimated through profit at Pakistan's jointly individual citizen and regional level. In addition, on behalf of the area examinations Nutrition and local health are estimated by health organizations (number of beds per worker and fundamental wellness units per worker), various sustenance consumption is estimated for the health examination of individuals. Researchers obtain data from the 2010-2011 Integrated budget survey and numerous interim statistical developments. The result is that the level of efficiency in health is too important. In order to limit this gaining imbalance, the unfair circulation of nutritional admission and health organizations affects the disparity in profit.

Chaudary et al. (2013) examined the impact of health indicators on the economic growth of Pakistan. For finding the relationship the y use OLS (ordinary least square method) Granger Causality technique. For this purpose, they use Pakistan's time series data from 1950-201 2. Therefore, they use some of these indicators (health expenditures, fertility rate, life expectancy, and infant mortality rate). GDP (per capita) expressively effected by life expectancy, fertility rate, investment on health sectors. Health expenditure also effect positively related with GDP but irrelevant to economic growth. There's negative link of infant mortality rate, per bed people on financial progress. The strategy of the paper was when there is increment of investment on wellbeing services it improves the economic growth too. Bhargava et al. (2001) researcher study wellbeing pointers as ASR (adult survival rates) on Gross Domestic Product (GDP) growing charges in numerous countries for 5-year intermission (1965-1990). The data analyzed was panel data on GDP sequence in light of acquiring power modifications and on trade rates. 1nitially, they built $\mathrm{u} p$ a system for demonstrating the between connections between GDP development rates and informative factors by rethinking the life expectancy - wage relationship. Second, models for development rates were assessed considering the collaboration amongst ASR and blacked GDP level; issues of endogeneity and turn around causality were tended to. In conclusion, they processed confidence interims advance ASR production speed effect and a parameter solidity measure associated. The findings showed promising results for ASR on GDP growth rates in low-paid countries. 


\section{Data and Methodology}

\subsection{Selection of Data and Variables}

Data has been obtained from WDI (World Development Indicators), with time series of 1990 to 2020. In this analysis uses the dependent variable GDP, while the independent fertility criteria are infant mortality, insurance costs, life expectancy and direct foreign investment.

Table 1. Data Description

\begin{tabular}{|c|c|c|c|c|}
\hline S.NO. & Variables & Time Period & Data Type & Source of Data \\
\hline 1. & GDP & $1990-2020$ & Time Series & WDI \\
\hline 2. & Fertility Rate & $1990-2020$ & Time Series & WDI \\
\hline 3. & Health Expenditure & $1990-2020$ & Time Series & WDI \\
\hline 4. & Infant Mortality Rate & $1990-2020$ & Time Series & WDI \\
\hline 5. & $\begin{array}{l}\text { Foreign Direct } \\
\text { Investment }\end{array}$ & $1990-2020$ & Time Series & WDI \\
\hline 6. & Life Expectancy & $1990-2020$ & Time Series & WDI \\
\hline
\end{tabular}

\subsection{Empirical Model}

The research aims to analyze health factors that influence economic development in Pakistan by using this equation:

$$
\begin{aligned}
& \text { GDP } \tau=\beta 0+\beta 1(F D I) \tau+\beta 2(M R) \tau+\beta 3(L E) \tau+\beta 4(H E) \tau+\beta 5(F R) \tau+\varepsilon \\
& \text { GDP }=\text { Gross Domestic Product } \\
& \text { FDI }=\text { Foreign Direct Investment } \\
& \text { MR }=\text { Mortality rate } \\
& \text { LE } \quad=\text { Life Expectancy } \\
& \text { HE } \quad=\text { Health Expenditure } \\
& \text { FR } \quad=\text { Fertility Rate }
\end{aligned}
$$

The model we developed in that GDP is dependent variable where as "foreign direct investment, mortality rate, life expectancy, health expenditure and fertility rate are independent variables. We apply the estimation on the above equation after checking the stationary of the variables.

The model we built in that GDP is a dependent variable, which includes independent variables such as "foreign direct investment, mortality rate, life expectancy, and health expenditure and fertility rate". After testing the variables, we add the approximation to the above equation.

\subsection{Empirical Technique}

We are going to examine whether the variables are stationary in order to estimate the effects of health spending on the economic growth of Pakistan. For this reason, we are using the Dicky Fuller Measure. The unit root is not fixed, so unit root factors become stable where there is no unit root. Life expectancy and mortality rate at level 1(0) are constant when all other factors are first difference (I). We use the ARDL method for estimating the effects on the model.

\subsubsection{ARDL (Autoregressive Distributed lag)}

In 1999 Pesaran and Shin presented the ARDL model, and in 2001, Persaran el. reviewed it. The advantage of the ARDL method is that the first distinction is not all the variables 1 (I). Instead, ARDL attempts to tackle the problem of serial correlation while having explanatory variables lags within the model for other independent or lagging variables. 


\subsubsection{ARDL Rules}

The most important obligation of ARDL was that auto correlation does not exist. Normal distribution of the data. Heteroscedasticity should not arise in the data.

Either on first differences I (0) or I (1), or both, data should be stationary. In addition, ARDL cannot be used if certain of the variables are stationary at second difference I (2).

\subsubsection{ARDL Simple Equation}

$\mathrm{Yt}=\beta \mathrm{o}+\beta_{1} \mathrm{y}_{\mathrm{t}-1}+\ldots .+\beta_{\mathrm{p}} \mathrm{y}_{\mathrm{t}-\mathrm{m}}+\alpha_{0} \mathrm{x}_{\mathrm{t}}+\alpha_{1} \mathrm{y}_{\mathrm{t}-1}+\alpha_{2} \mathrm{x}_{\mathrm{t}-2}+\ldots .+\alpha_{\mathrm{q}} \mathrm{x}_{\mathrm{t}-\mathrm{n}}+\varepsilon_{\mathrm{t}}$

\section{Empirical Results}

The data of the present study was fed into the E-views 9 for the mathematical calculation. All the data is gathered from world development indicators for the past 30 years (1990 to 2020). Initially the data is converted into logically acceptable format in order to understand the working position effectively. The statistical analysis of the variables, with the mean, limit, minimum and standard deviations from the results, is given in Table 2.

Table 2. Descriptive Statistics

\begin{tabular}{lllll}
\hline Variables & Mean & Maximum & Minimum & Standard Deviation \\
\hline GDP & 939.650 & 1178.789 & 741.801 & 137.338 \\
HE & 2.745 & 3.401 & 2.503 & 0.260 \\
FR & 8.946 & 66.33 & 3.550 & 16.225 \\
LE & 63.514 & 106.20 & 64.20 & 1.987 \\
MR & 83.575 & 106.20 & 64.20 & 12.980 \\
FDI & 1.136 & 3.668 & 0.382 & 0.854 \\
\hline
\end{tabular}

The table 2 shows the descriptive statistics about the variables, variables are GDP, mortality rate, life expectancy, foreign direct investment, health expenditure and fertility rate. The mean value of GDP is 939.650, maximum value is I 178.789, minimum value is 741.801 and the value of standard deviation is 137.338 . The mean value of $\mathrm{HE}$ is 2.745 , maximum value is $3.401,2.503$ is minimum value and the value of standard deviation is 0.260 . The value of standard deviation is 137.338 . The mean value of FR is $8.946,66.33$ is the maximum value, 3.550 is minimum value and the value of standard deviation is 16.225 . The mean value of $L E$ is 63.514 , maximum value is 106.20 , minimum value is 64.20 and the value of standard deviation is 1.987 . The mean value of $\mathrm{M} \mathrm{R}$ is 83.575 , maxi mu $\mathrm{m}$ value is 106.20, Minimum value is 64.20 and the value of standard deviation is 12.980 . The mean value of WDI is 1.136 , 3.668 is the maximum value, 0.382 is minimum value and the value of standard deviation is 0.854 .

Table 3. Results of Unit Root

\begin{tabular}{llll}
\hline Variables & At Level & $1^{\text {st }}$ Difference & Decision \\
\hline GDP & 0.4643 & $-2.1487^{* * *}$ & I $(1)$ \\
Mortality rate, infant & $(0.9812)$ & $(0.0328)$ & \\
& $-3.9809^{*}$ & - & $\mathrm{I}(0)$ \\
Fertility rate & $(0.0057)$ & $-5.0887^{*}$ & \\
& -1.9098 & $(0.0004)$ & $\mathrm{I}(1)$ \\
Life expectancy & $(0.3216)$ & - & $\mathrm{I}(0)$ \\
\hline
\end{tabular}




\begin{tabular}{llll}
\hline Variables & At Level & $1^{\text {st }}$ Difference & Decision \\
\hline Health expenditure & -2.1987 & $-4.013032^{*}$ & I (1) \\
Foreign direct & $(0.2114)$ & $(0.0049)$ & \\
investment & -2.7447 & $-3.364001^{* *}$ & I (1) \\
\hline
\end{tabular}

*shows intercept, **shows trend and intercept, *** shows none

In the table 3. the estimated ADF statistics with their p-value are presented. The table indicates that mortality and life expectancy are constant at the same stage while GDP, FDI are stationary in the first difference I (1), thus denying the zero-unit root hypothesis respectively. At level or at the first difference, both variables are stationary.

In order to verify the behaviour of residuals we have applied diagnostic tests, which gives the information regarding white noise error term.

Table 4. Diagnostic-Correlation Test

\begin{tabular}{llll}
\hline F-statistic & 0.064703 & Prob. F (2,15) & 0.9376 \\
Obs*R-squared & 0.222384 & Prob. Chi-Square (2) & 0.8948 \\
\hline
\end{tabular}

The value of Obs*R-squared 0.222354 chi-Square is insignificant $(0.8948)$. So, there is no correlation between dependent and independent variables. The chi square is negligible in the importance of Obs*R $222354(0.8948)$. There is, however, little connection between dependent and single variables.

Table 5. Diagnostic- Heteroscedasticity Test

\begin{tabular}{llll}
\hline F-statistic & 0.420448 & Prob. F (8,17) & 0.8929 \\
Obs*R-squared & 4.294591 & Prob. Chi-Square (8) & 0.8296 \\
Scaled explained SS & 0.982078 & Prob. Chi-Square (8) & 0.9984 \\
\hline
\end{tabular}

If the probability value of Obs* $\mathrm{R}$-squared is insignificant, heteroscedasticity is not present. In this article, the probability y value of the square obs* $\mathrm{R}$ is negligible at the Chi-square level $(0.8296)$ in compliance with the Breusch Pagan Godfrey test, hence there is no hetro present in its model. The probability and value of the obs* $\mathrm{R}$ square at chi-square level (0.8296) is negligible according to the Breusch pagan Godfrey test. Thus, there is no hetro-present in the model.

Table 6. ARDL Estimates

\begin{tabular}{lllll}
\hline Variable & Coefficient & Std. Error & t-Statistic & Prob. \\
\hline$\Delta$ Ln (GDP (-1)) & 0.456186 & 0.255687 & 1.784160 & 0.0923 \\
$\Delta \operatorname{Ln}($ FR) & 0.026368 & 0.020630 & 1.278159 & 0.2184 \\
$\Delta \operatorname{Ln}($ FDI) & 0.025401 & 0.010903 & 2.329613 & 0.0324 \\
$\Delta \operatorname{Ln}(\mathrm{HE})$ & -0.025135 & 0.060495 & -0.415486 & 0.6830 \\
$\Delta \mathrm{Ln}(\mathrm{LE})$ & 37.437229 & 20.244171 & 1.849284 & 0.0819 \\
$\Delta \mathrm{Ln}(\mathrm{MR})$ & -2.904496 & 1.008730 & -2.879360 & 0.0104 \\
CointEq (-1) & -0.800082 & 0.253951 & -3.150534 & 0.0058 \\
\hline
\end{tabular}

Model chosen for ARDL $(2,0,0,1,0)$. The short-term relationship between dependent and independent variables has been shown in the table above. Estimated short-term affiliation factors are important for GDP, FDI, LE, and MR, with significant positive impacts on GDP from fertility, foreign direct investment, and life expectancy. Health and spiritual expenses affect adversely, while MR has an important probability value of 0.0010 . As if there is a $1 \%$ increase in FR, the GDP would be increased by 0,026 , if the FDI would increase by $1 \%$ then the GDP would grow by 0,025 Further rise in spending in the healthcare sector, which ensures that economic activity will also rise. If the life expectancy is 
increased by $1 \%$, so GDP will be increased by 37.43 . If healthcare spending increases by $1 \%$, GDP would be adversely affected by $-0,025$. As in previous investigations, it has also been reported that there is a poor relationship between health expenditures and economic development, using co-integration on process. The co-integration ion method was used by Arisoy et al. [2018]. Kar and Taban [2018] to validate the connection between health and economic development spending in Turkey; the negative relationship between health and economic growth was noted. Previous study has also found that the child mortality rate is related adversely to the OLS system. The findings show that 1 infant mortality has a negative effect on GDP per capita, but it has a critical impact (Raza Kashif et al).

Table 7. ARDL Bounds Test Results

\begin{tabular}{lll}
\hline Test Statistic & Value & K \\
\hline F-statistic & 9.309085 & 5 \\
Critical Value Bounds & & \\
Significance & I (0) Bound & I (1) Bound \\
$10 \%$ & 2.26 & 3.35 \\
$5 \%$ & 2.62 & 3.79 \\
$2.5 \%$ & 2.96 & 4.18 \\
$1 \%$ & 3.41 & 4.68 \\
\hline
\end{tabular}

The findings of F-statistic demonstrate the long-lasting relationship between the variables when the critical value limit is less than the F-state value. If the F-stat value is 9.309055, then the critical value is higher, which indicates that the variables are co-integrated, while the null hypothesis is dismissed. The long nine link between the variables exists.

Table 8. Long-Run Coefficients of ARDL

\begin{tabular}{lllll}
\hline Variable & Coefficient & Std. Error & t-Statistic & Prob. \\
\hline LNFR & 0.032957 & 0.017689 & 1.863142 & 0.0798 \\
LNFDI & 0.031748 & 0.010005 & 3.173058 & 0.0056 \\
LNHE & -0.031415 & 0.074793 & -0.420030 & 0.6797 \\
LNLE & -12.510631 & 4.528335 & -2.762744 & 0.0133 \\
LNMR & -3.630249 & 0.916243 & -3.962103 & 0.0010 \\
C & 74.544663 & 22.821211 & 3.266464 & 0.0045 \\
\hline
\end{tabular}

Selected model for ARDL $(2,0,0,0,1,0)$. As in the long run table FR is significant with the probability value of 0.0795.FDI is significant with the probability value 0.0056 . LE is negative with the significant probability value of 0.0133. As in the previous researches, using multiple regression analysis, there was negative impact of life expectancy on economic growth (Babatunde, 2014). MR is negative but significant with the probability value 0.0010 . Whereas HE is negative and insignificant with the probability value of 0.6797 . In the developing countries 'income of people is low so they face a lot of health problems but unable to pay for their treatment, the y cannot actively participate in economic growth activities.

In order to check the stability of model, cusum stability tests are applied at $0.05 \%$ of significance level. 


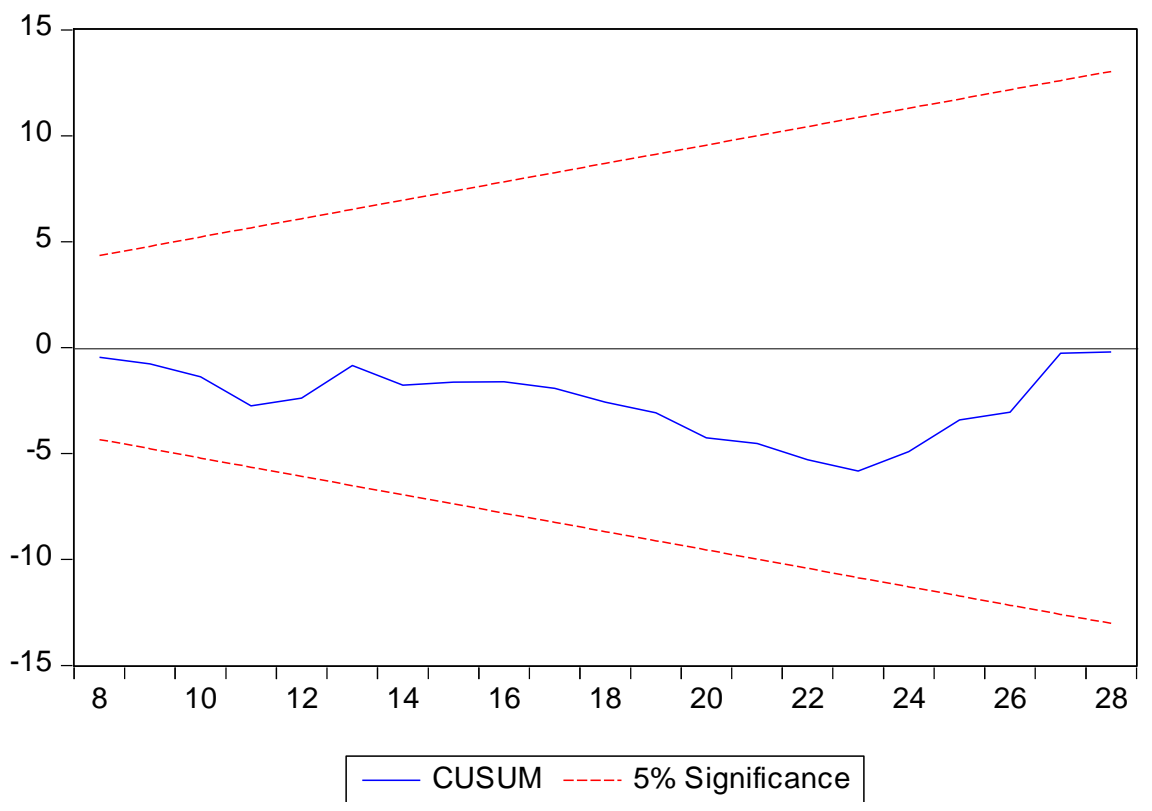

Fig. 1. CUSUM - Model Stability Test

Brown et.al (1975). The above figure shows CUSUM plot to verify the consistency of the chosen ARDL model by using Recursive estimates. The blue line lies, as seen in the above figure, between 5\% and the significant amount, which indicates that the model suits the $5 \%$.

\section{Conclusion}

Health indicator is the measure which is designed to summarize information about a given prioritized topic in population health or health system performance. The data is time series data which is collected from world development indicator form the time period of 1990 to 2020.This study involves descriptive statistics and cointegration technique as the prerequisite tests, unit root test is involved to check the stationarity of the data. The ARDL model is used in this paper after checking the stationarity and the bound test. The result shows both long run and short run relationship. Wellbeing predictor is the test to analyze knowledge on a priority issue of health promotion or the efficiency of the health systems. In long run relationship, mortality rate and health expenditure have the negative impact on the growth rate of the country and all the other variables have positive impact on the growth rate of Pakistan which means that the health indicator has overall progress effect on the development of the nation. In the long term the death rate and health spending have a negative impact on the country's growth rate, and all the other variables have a positive effect on Pakistan's growth rate, meaning the health metric has an overall effect on the nation's progress. In the short term, all factors except health spending have important values. Health spending, life expectancy and the rate of death have a negative effect on the country's growth rate, and foreign direct investment and fertility have a positive impact on Pakistan's growth rate. Overall, the growth rate does not rely strongly on the health measure in the short term, although it has a poor impact of variables on the country's growth rate. The factors in the long term are a big stimulus for the country's growth. Bhargava et al. (2001), finds relationship between the rate of survival of adults and economic development has been positive. If the adult mortality figure is combined for the future, these outcomes should be equivalent. However, the rate of maturity is a negative link to economic development. Until then, death of the tyke has massively affected the prospect. Workforce production is significantly smaller than population increase. As a result, the high fertility rate reduces economic development by placing extra burdens on terrible assets. Arisoy et al. (2010) Studied the impact on economic growth of the mortality rate; shows that the elevated death rate decreases economic development by rising the timeframe. As a result, people engage in activities that produce here and now have long-term benefits. Concentrate mortality too, which is the networks and adult deaths affects economic growth through education as well as investment in physical and human resources. 


\section{Policy Implication}

The policy implications of the examination are that nations that want high levels of per capita income, they can do this, particularly if current stock is in decline, by broadening and improving the stock of human health. Moreover, consideration is also the reason why the per capita GDP is determined by a fairly modest portion of general wellbeing intake. Exploration implies that human capital's health must be integrated into planning conditions, since it is also a vital component of human capital. Moreover, there is an immediate need for research to dismantle Pakistan's rise in welfare demand, which means that there is no thinking for a long time.

\section{References}

Abbas, Q., \& Foreman-Peck, J. S. (2008). Human capital and economic growth: Pakistan 1960-2003. Lahore Journal of Economics, 13(1), 1-27.

Abbas, Q., \& Mujahid-Mukhtar, E. (2000). The role of human capital in economic growth: a comparative study of Pakistan and India [with Comments]. The Pakistan development review, 451-473.

Ahsan, H., \& Idrees, D. M. (2014). Impact of Health on Earnings: Individual and District Level Analysis for Pakistan.

Ali, M. A., Ullah, M. I., \& Asghar, M. A. (2017). Effect of health expenditure on GDP, a panel study based on Pakistan, China, India and Bangladesh. Int J Health Econ Policy, 2(2), 57-62.

Arisoy, İ., Ünlükaplan, İ., \& Ergen, Z. (2010). The relationship between social expenditures and economic growth: a dynamic analysis intended for 1960-2005 period of the Turkish economy. MaliyeDergisi, 158, 398-421.

Barro, R. J. (1991). Economic growth in a cross section of countries. The quarterly journal of economics, 106(2), 407-443.

Bhargava, A., Jamison, D. T., Lau, L. J., \& Murray, C. J. (2001). Modeling the effects of health on economic growth. Journal of health economics, 20(3), 423-440.

Brenner, M. H. (2005). Commentary: Economic growth is the basis of mortality rate decline in the 20th centuryexperience of the United States 1901-2000. International journal of epidemiology, 34(6), 1214-1221.

Chaudhry, M. O., Zahir, M., Farooq, F., \& Arif, R. (2013). Contribution of Health Outcomes to Economic Growth in Pakistan. Pakistan Journal of Social Sciences (PJSS), 33(2).

Grossman, M. (1972). On the concept of health capital and the demand for health. Journal of Political economy, 80(2), 223-255.

Kar, M., \& Taban, S. (2003). The impacts of the disaggregated public expenditure on economic growth. Ankara University Faculty of Political Science, 53(3), 145-169.

Khan, M. S., Amjad, R., \& Din, M. U. (2005). Human capital and economic growth in Pakistan [with comments]. The Pakistan development review, 455-478.

Lucus Jr, R. E. (1988). On the Mechanics of Economic Development. Journal of (1988).

Mincer, J. (1996). Economic development, growth of human capital, and the dynamics of the wage structure. Journal of Economic Growth, 1(1), 29-48.

Musila, J. W., \& Belassi, W. (2004). The impact of education expenditures on economic growth in Uganda: evidence from time series data. The Journal of Developing Areas, 123-133.

Renny, O. R. (2012). The Role of Health in Economic Growth and Development. A Term Paper, Department of Masters public and International Affairs, University of Lagos, Nigeria.

Sachs, J. D., Mellinger, A. D., \& Gallup, J. L. (2001). The geography of poverty and wealth. Scientific American, 284(3), 70-75. 
World Health Organization. (1999). The world health report: 1999: making a difference. World Health Organization.

World Health Organization. (2016). World health statistics 2016: monitoring health for the SDGs sustainable development goals. World Health Organization.

Zhou, B., Lu, Y., Hajifathalian, K., Bentham, J., Di Cesare, M., Danaei, G., ... \& Gaciong, Z. (2016). Worldwide trends in diabetes since 1980: a pooled analysis of 751 population-based studies with 4.4 million participants. The Lancet, 387(10027), 1513-1530. 